\title{
BMJ Open Exploring the characteristics of the high- cost population from the family perspective: a cross-sectional study in Jiangsu Province, China
}

\author{
Yudong Miao, ${ }^{1,2}$ Dongfu Qian, ${ }^{2}$ Sandeep Sandeep, ${ }^{1}$ Ting Ye, ${ }^{1}$ Yadong Niu, ${ }^{1}$ \\ Dan $\mathrm{Hu}^{2}{ }^{2}$ Liang Zhang ${ }^{1}$
}

To cite: Miao Y, Qian D, Sandeep S, et al. Exploring the characteristics of the high-cost population from the family perspective: a crosssectional study in Jiangsu Province, China. BMJ Open 2017;0:e017185. doi:10.1136/ bmjopen-2017-017185

- Prepublication history for this paper is available online. To view these files, please visit the journal online (http://dx.doi. org/10.1136/bmjopen-2017017185).

Received 7 April 2017

Revised 18 September 2017

Accepted 20 September 2017

CrossMark

${ }^{1}$ School of Medicine and Health Management, Tongji Medical College, Huazhong University of Science and Technology, Wuhan, Hubei, China

${ }^{2}$ School of Health Policy and Management, Nanjing Medical University, Nanjing, Jiangsu, China

Correspondence to Professor Liang Zhang; jiangpanzhuyi@126.com

\section{ABSTRACT}

Background Across a range of healthcare settings, 5\% of the population accounts for half of healthcare spending: these patients are identified as a 'high-cost population'. Characterising high-cost users is essential for predicting potential high-cost patients and the development of appropriate interventions to improve the management and financing of these patients.

Objective This cross-sectional study aimed to explore the characteristics of this high-cost population from a family perspective in China and provide suggestions for social health insurance policy development.

Methods This study used data from the Fifth Health Service Investigation of Jiangsu Province (2013), and 12600 families were enrolled for analysis. Households whose medical expenditures were among the top $5 \%$ were identified to be high-cost families. A t-test, a $\mathrm{X}^{2}$ test, and a binary logistic regression were used.

Results High-cost families $(n=631,5 \%)$ accounted for $44.9 \%$ of the total medical expenditure of sampled families. High-cost families had 3.2 members and 1.2 chronic disease patients per household, which is significantly more than the 2.9 members and 0.7 people in the remaining families, respectively $(p<0.05)$. Bi-weekly emergency department visits and annual hospitalisations preceding the household investigation of high-cost families were 1.19 and 0.98 per household, which is significantly more than the 0.68 and 0.17 of the remaining families, respectively $(p<0.05)$. A binary logistic regression indicated that the number of family members (OR 1.152), the number of chronic disease patients (OR 1.508), bi-weekly emergency department visits (OR 1.218), and annual hospitalisations (OR 4.577) were associated with high costs.

Conclusion The $5 \%$ high-cost families in Jiangsu Province accounted for approximately half of medical expenditures. The effectiveness of Chinese Social Health Insurance in lowering high-cost families' risk of catastrophic health expenditure was modest. Policymakers need to ascertain the priority of lowering the burden of high-cost families' out-of-pocket expenses through improving the reimbursement proportion and reducing avoidable medical services.
Strengths and limitations of this study

- This was a very large study involving 12600 families and the first to investigate high-cost populations in a Chinese healthcare setting.

- The study not only introduced the concept of the high-cost patient to China but also explored the characteristics of this population by quantitative measurement.

- The overall study design was conducted from the family perspective, which plays a significant and extraordinary role in health policymaking in China and many other Eastern Asian countries.

- The data were collected only in Jiangsu Province, which was an economically developed province and might not be representative of other economically developing areas in China. Further research in other economically developing areas or at the national level is needed to provide comprehensive evidence for policymakers.

- Although high-cost populations have attracted the attention of many policymakers and researchers from the WHO and the USA during the past decades, there was no consensus on the concept of the highcost population and standards of identification. More theoretical studies should be carried out to determine and popularise the concept.

\section{BACKGROUND}

Previous studies have shown that across a range of healthcare settings and populations, a small number of patients account for a disproportionate amount of costs. ${ }^{1}$ Within the USA, $5 \%$ of the population accounts for approximately half of healthcare spending $^{12}$; these patients are known as the 'high-cost population'. ${ }^{3}$ A few studies from Hong Kong and several European countries also presented similar findings. ${ }^{2}{ }^{4}$ Usually, these high-cost patients have multiple chronic conditions and need more health services than the average person. ${ }^{45}$ Their high need for medical services and the high cost of 


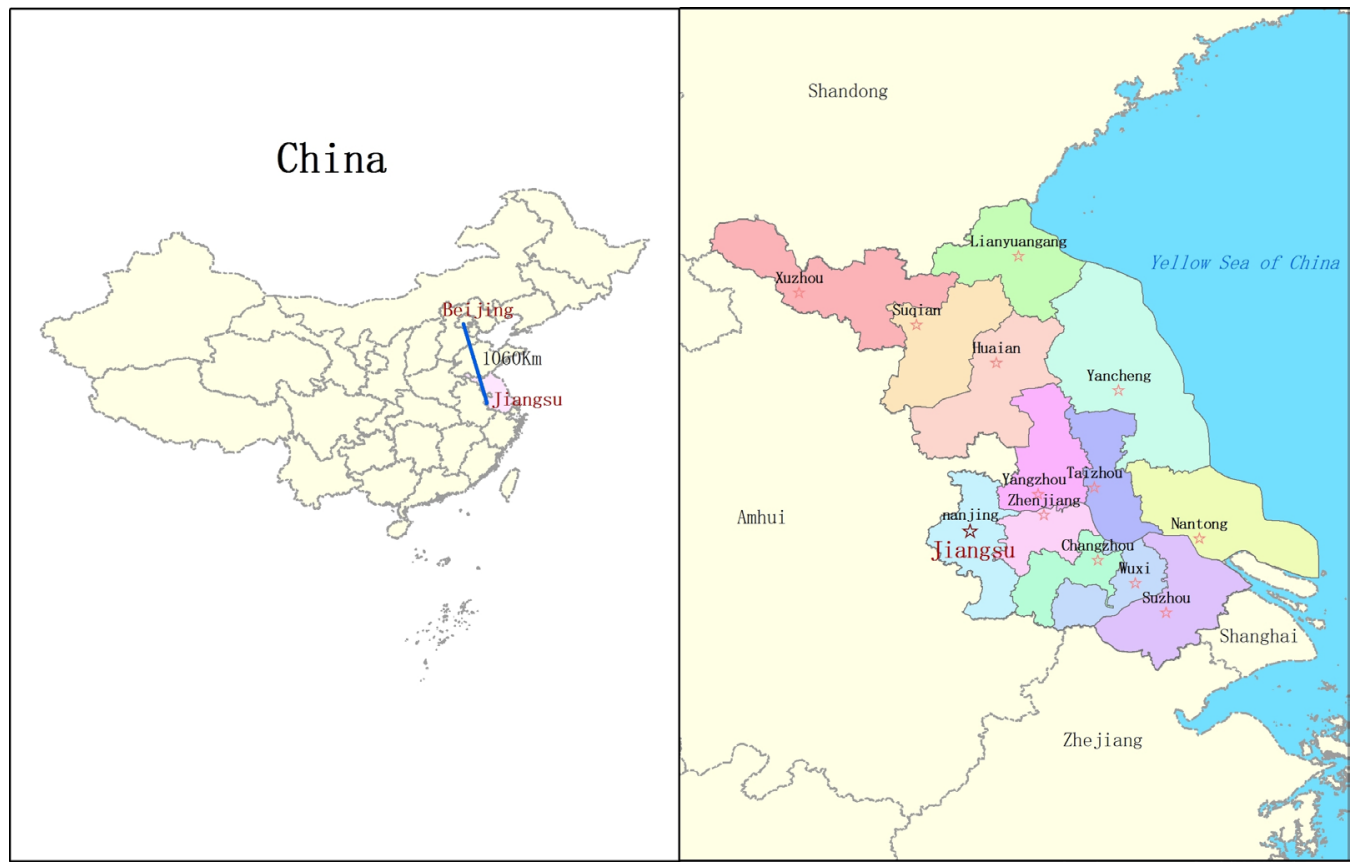

Figure 1 Map of Jiangsu, China: geographic distribution of study places.

providing these services have made them a key population for health and medical insurance policymaking in many US states. ${ }^{2}$ Identifying the characteristics of this particular population was considered to be essential because: first, quite a few health projects aimed at reducing the irrational use of medical services have been implemented by medical insurance policymakers in the USA, Hong Kong and some European countries, with the result that some medical insurance funding was saved by these projects; ${ }^{6}$ and second, the saved funding was re-invested into medical insurance funds so as to support these health projects and lower the economic burden of disease in the high-cost population. ${ }^{7}$ Although the high-cost population has attracted the attention of many researchers and medical insurance policymakers, no study has been undertaken on the high-cost population in the Chinese mainland. Previous studies have been carried out at the individual level; however, in the context of China and many Eastern Asian countries, family as a social function unit is decisive in family members' healthcare utilisation and medical expenditures. ${ }^{89}$ The characteristics of these families, which are essential to health policymakers for predicting and financing future high-cost populations, are still unknown. ${ }^{10}$

China is a country with 401517330 families. ${ }^{11}$ Exploring the characteristics of high-cost patients from the family perspective is likely to be of particular interest to Chinese medical insurance policymake. In the past few decades, the Chinese government has attempted to reduce the economic burden of disease and lower the financial risk for patients by establishing a Social Health Insurance (SHI) system covering all families. The SHI consists of the Basic Medical Insurance System for Urban Workers (since 1998), the New Rural Cooperative Medical Service System for Rural Residents (since 2003), and the Basic Medical Insurance System for Urban Residents (since 2007). Since

Table 1 Sampled counties/districts and families in this study

\begin{tabular}{llllll}
\hline Investigation sites & No. of families & $\begin{array}{l}\text { Average } \\
\text { population per } \\
\text { family }\end{array}$ & Investigation sites & No. of families & $\begin{array}{l}\text { Average } \\
\text { population per } \\
\text { family }\end{array}$ \\
\hline Gaochun District & 900 & 3.0 & Gusu District & 600 & 2.5 \\
\hline Liyang County & 900 & 2.7 & Chongchuan District 600 & 2.9 \\
\hline Haimen County & 900 & 2.3 & Xishan District & 600 & 3.3 \\
Gaoyou County & 900 & 2.8 & Xinpu District & 600 & 2.9 \\
\hline Danyang County & 900 & 3.2 & Jinhu County & 600 & 2.5 \\
\hline Jiangyan County & 900 & 2.6 & Tinghu District & 600 & 3.1 \\
\hline Qinhuai District & 600 & 2.6 & Yangzhong County & 600 & 3.2 \\
\hline Jiangyin County & 600 & 3.3 & Qishuyan District & 600 & 2.8 \\
\hline Pizhou County & 600 & 3.2 & Sucheng District & 600 & 3.4 \\
\hline
\end{tabular}




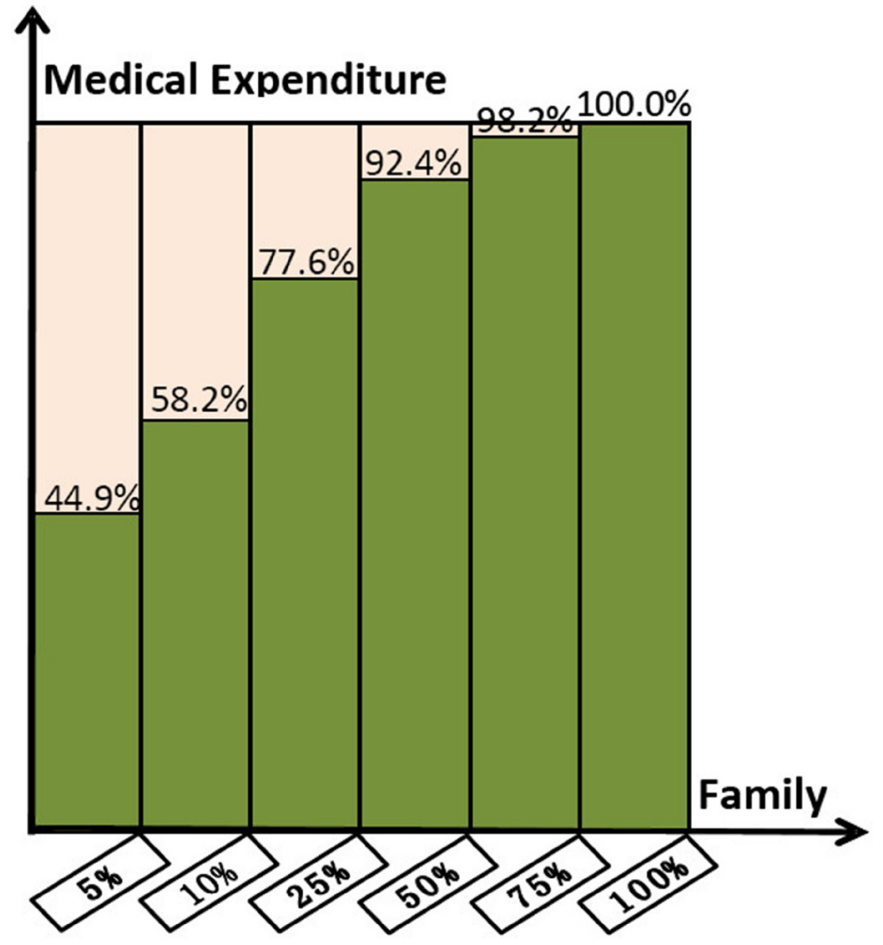

Figure 2 Overall distribution of medical expenditures referring to the sampled families.

the 2009 healthcare reform, the SHI has made impressive progress and $>95 \%$ of Chinese residents have been covered. After the establishment of SHI, medical expenditures in the Chinese mainland at present are paidpaid jointly by SHI reimbursement and patient out-of-pocket payment. Moreover, outpatient and inpatient services are reimbursed separately, and the reimbursement proportion of inpatient expenditures is usually much higher than outpatient expenditures. Improving the utilisation efficiency of SHI funds is therefore thought to be crucial in lowering the economic burden of diseases of the residents. However, SHI faces substantial challenges due to a noticeable defect. ${ }^{12} 13$ In most regions of the Chinese mainland, SHI policymakers consider all patients to be the same when it comes to reimbursement: no matter how much medical expenditure a patient requires, the expenses will be reimbursed in the same proportion. Policymaking in this way seems fair; however, for those families with a high need for medical services and consequently high levels of medical expenditure, the out-ofpocket expenses after SHI reimbursement is sufficient to cause a patient or family to become impoverished. As a result of this defect in SHI policy design, high-cost families, which need the SHI reimbursement the most, cannot obtain sufficient reimbursement of medical insurance funds if they are to avoid catastrophic health costs. This is one of the reasons why 'Costly access to healthcare' is and will still be the main problem to be settled for the next phase of Chinese healthcare reform. ${ }^{1415}$

Therefore, to attract the attention of Chinese health policy researchers and to inform SHI policymaking, this study sought to investigate the household expenditures and income, family population composition, healthcare utilisation, and SHI coverage of a large number of Chinese families. The objectives were to ${ }^{1}$ characterise the $5 \%$ highest cost families regarding their medical expenditures, family population composition, healthcare utilisation, and SHI coverage, and ${ }^{2}$ determine the associations between medical expenditures, family population composition, healthcare utilisation, SHI coverage, family annual income and family domicile among the population.

\section{METHODS}

\section{Population and data sources}

This family perspective study used household investigation data from the Fifth Health Service Investigation of Jiangsu Province (2013) (figure 1). The 2013 investigation used a multi-stage random cluster sampling method and was conducted from August to November 2013. Eighteen counties/districts from all 102 counties/districts of Jiangsu Province, five towns/sub-districts within each selected county/district, and two villages/communities within each selected town/sub-district were chosen as investigation sites. According to the population size, the enrolled 18 counties/districts were divided into two categories: if the population size of a county/district was larger than the average, 90 families within each village of the county/district were randomly selected; if not, 60 families within each village were randomly selected. In total, this investigation enrolled 18 counties (six counties with a large population and 12 counties with a small population), 90 towns/sub-districts, 180 villages/ communities, and 12600 families (table 1). Each county health bureau was responsible for organising their local investigation. The household investigation questionnaire used in Jiangsu Province was developed by the National Health and Family Planning Commission of

Table 2 Medical expenditure of sampled families

\begin{tabular}{|c|c|c|c|}
\hline Medical expenditure & $n=631(5 \%)$ & $\mathrm{n}=11986(95 \%)$ & p Value \\
\hline Total medical expenditure (yuan) & 19593622.7 & 24097853.0 & - \\
\hline $\begin{array}{l}\text { Medical expenditure per household } \\
\text { (yuan, } x \pm S \text { ) }\end{array}$ & $31051.7 \pm 33546.9$ & $2010.5 \pm 2273.9$ & 0.000 \\
\hline $\begin{array}{l}\text { Proportion of medical expenditure in household income remaining } \\
\text { after subsistence needs }(\%, x \pm s)\end{array}$ & $0.469 \pm 0.210$ & $0.079 \pm 0.096$ & 0.000 \\
\hline
\end{tabular}




\begin{tabular}{|c|c|c|c|}
\hline \multirow[b]{2}{*}{$\begin{array}{l}\text { Population } \\
\text { composition }\end{array}$} & $\begin{array}{l}\text { High-cost } \\
\text { families }\end{array}$ & $\begin{array}{l}\text { Remaining } \\
\text { families }\end{array}$ & \multirow[b]{2}{*}{ p Value } \\
\hline & $n=631(5 \%)$ & $\begin{array}{l}n=11986 \\
(95 \%)\end{array}$ & \\
\hline $\begin{array}{l}\text { No. of family } \\
\text { members }\end{array}$ & $3.2 \pm 1.4$ & $2.9 \pm 1.3$ & 0.000 \\
\hline $\begin{array}{l}\text { Old-age dependency } \\
\text { ratio }(\%, x \pm S)\end{array}$ & $0.436 \pm 0.396$ & $0.348 \pm 0.402$ & 0.000 \\
\hline $\begin{array}{l}\text { Chronic disease } \\
\text { patients per } \\
\text { household }(x \pm s)\end{array}$ & $1.24 \pm 0.84$ & $0.7 \pm 0.75$ & 0.033 \\
\hline $\begin{array}{l}\text { Proportion of chronic } \\
\text { disease patients per } \\
\text { household }(\%, x \pm s)\end{array}$ & $45.2 \pm 34.6$ & $28.8 \pm 33.9$ & 0.013 \\
\hline
\end{tabular}

the People's Republic of China. Well-trained interviewers who were township hospital physicians, with support from village health workers, visited households and invited the family's head or the member who was most familiar with the healthcare utilisation and spending of the family to participate in the survey. Face-to-face interviews using a structured questionnaire were conducted to collect information about household medical expenditures and other expenditures, household income, family population composition, healthcare utilisation, and social health insurance coverage.

\section{Statistical analysis}

We categorised families as 'high cost' if their total medical expenditures were among the top 5\% for all families assessed. ${ }^{16-19}$ We used $\chi^{2}$ and t-tests in bivariate analyses to compare high-cost families with the remaining families, by medical expenditure, family population composition, medical care utilisation, and SHI coverage. A value of $\mathrm{p}<0.05$ was considered to be statistically significant. Data were analysed with SPSS version 19.0 (SPSS Inc, Chicago, USA; http://www.spss.com).

\section{Ethics statement}

The Fifth Health Service Investigation of Jiangsu Province (2013) was the regular work of the Health and Family Planning Commission of Jiangsu Province, which was approved by the National Health and Family Planning Commission of the People's Republic of China and the National

\begin{tabular}{llll}
\hline Table 4 & Medical care utilisation of sampled families \\
\hline & $\begin{array}{l}\text { High-cost } \\
\text { families } \\
\mathbf{n = 6 3 1}(\mathbf{5 \% )})\end{array}$ & $\begin{array}{l}\text { Remaining } \\
\text { families } \\
\mathbf{n}=\mathbf{1 1 9 8 6}\end{array}$ & \\
$\mathbf{( 9 5 \% )}$ & p Value \\
\hline utilisation & $1.19 \pm 0.84$ & $0.68 \pm 0.76$ & 0.000 \\
\hline $\begin{array}{l}\text { 2-weekly emergency } \\
\text { department visits per } \\
\text { household }\end{array}$ & & & \\
$\begin{array}{l}\text { Annual hospitalisations } \\
\text { per household }\end{array}$ & $0.98 \pm 0.89$ & $0.17 \pm 0.43$ & 0.000 \\
\hline
\end{tabular}

Bureau of Statistics of the People's Republic of China. All enrolled families were given a letter explaining the study, and they gave written informed consent before the household investigation. The authors were permitted by the Health and Family Planning Commission of Jiangsu Province to select indicators related to the topic of this study from the overall database anonymously and use them in academic research.

\section{RESULTS}

\section{Household medical expenditures}

In this study, household medical expenditures refer to the total expenditures of family members to pay for medical treatment (including drug costs), hospitalisation, disease prevention, primary care services for pregnant women and pregnancy, children's healthcare and other expenses related to medical care. figure 2 illustrates the overall distribution of medical expenditures referring to the sampled families. High-cost families $(n=631$, $5 \%$ ) accounted for $44.9 \%$ of total healthcare spending in 2012. Table 2 shows that the average healthcare cost of high-cost families was $31051.7 \pm 33546.9$ yuan, which was significantly higher than the $2010.5 \pm 2273$.9yuan of the remaining families $(\mathrm{n}=11969,95 \%, \mathrm{p}<0.05)$. Moreover, high-cost families faced greater financial risk than the remaining $95 \%$ of families. The results showed that high-cost families' medical expenses accounted for $46.9 \%$ of the household income that remained after subsistence needs, which was significantly higher than the $7.9 \%$ of the remaining families $(\mathrm{p}<0.05)$.

\section{Family population composition}

As shown in table 3, high-cost families were extended families with more elderly members in aggregate, when compared with the remaining $95 \%$ of families. High-cost families in this provincial investigation had $3.2 \pm 1.4$ family members per household, which was significantly more than the $2.9 \pm 1.3$ members of the remaining families $(p<0.05)$; old-age dependency ratio per household of high-cost families was $0.436 \pm 0.396$, which was significantly higher than the $0.348 \pm 0.402$ of the remaining families $(p<0.05)$. The prevalence of chronic conditions was greater among high-cost families than among the remaining $95 \%$ of families. High-cost families had $1.24 \pm 0.84$ patients with chronic conditions per household, which was significantly more than the $0.7 \pm 0.75$ of the remaining families $(\mathrm{p}<0.05)$; the percentage proportion of chronic disease patients per household of highcost families was $45 \pm 35 \%$, which was significantly higher than the $29 \pm 34 \%$ of the remaining families $(p<0.05)$.

\section{Medical service utilisation}

Table 4 shows that high-cost families needed more outpatient services paired with inpatient services. Bi-weekly emergency department visits per household preceding the household investigation of high-cost families was $1.19 \pm 0.84$, which was significantly more than the $0.68 \pm 0.76$ 
Table 5 Social Health Insurance (SHI) coverage of sampled families

\begin{tabular}{|c|c|c|c|c|c|}
\hline \multirow[b]{2}{*}{ SHI } & \multicolumn{2}{|c|}{ High-cost families $n=631(5 \%)$} & \multicolumn{2}{|c|}{ Remaining families $n=11986(95 \%)$} & \multirow[b]{2}{*}{ p Value } \\
\hline & No. of families & Ratio (\%) & No. of families & Ratio (\%) & \\
\hline Covered & 614 & 97.3 & 11688 & 97.5 & 0.744 \\
\hline
\end{tabular}

of the remaining families $(\mathrm{p}<0.05)$; annual hospitalizations preceding the household investigation per household of high-cost families was $0.98 \pm 0.89$, which was significantly more than the $0.17 \pm 0.43$ of the remaining families $(\mathrm{p}<0.05)$.

\section{SHI coverage}

Table 5 presents the SHI coverage of the sampled families: $97.3 \%$ of high-cost families were covered by SHI, which was not significantly different from the $97.5 \%$ of the remaining families $(p>0.05)$.

\section{Factors associated with the high medical expenditure of high-} cost families

This study explored factors associated with the high medical expenditures of high-cost families using a binary logistic regression model (table 6). The regression model used a stepwise selection and used high-cost families and remaining families as the two explained variables; number of family members, number of chronic disease patients per household, 2-week emergency department visits per household, and annual hospital admissions per household were taken as potential predictors; and family annual income and family domicile (urban/rural) were used as controlled variables. In general, the study found that families with a larger population (OR 1.152, 95\% CI 1.084 to 1.223 ), more chronic disease patients (OR 1.508, 95\% CI 1.296 to 1.754 ), and which utilised more outpatient services (OR 1.218, 95\% CI 1.049 to 1.415 ) and inpatient services (OR 4.577, $95 \%$ CI 4.082 to 5.133) were more likely to be high-cost families. Family annual income and family domicile did not have a significant impact on whether or not a family became a high-cost family.

\section{DISCUSSION}

In the Chinese healthcare setting, the family is usually treated as a whole for financing and reimbursement purposes. The characterisation of high-cost families has implications for SHI policy development. This study indicated that the top $5 \%$ highest cost families in the Fifth Health Service Investigation of Jiangsu Province (2013) accounted for approximately half of the total medical expenses. This finding was consistent with the results reported by Zulman ${ }^{1}{ }^{1}$ and Feder $(2011) .{ }^{2} \mathrm{We}$ found that the average proportion of medical expenditures in household income remaining after subsistence needs of high-cost families and the remaining families have been accounted for was $46.9 \%$ and $6.9 \%$, respectively. According to the WHO, a health expenditure will be viewed as catastrophic whenever it is $\geq 40 \%$ of a household's non-subsistence income, ie, the income available for basic needs have been met. ${ }^{20}$ The present study indicates that high-cost families have a greater likelihood of catastrophic health expenditure. In one international perspective study, $\mathrm{Xu}$ et $a l^{21}$ proposed that even small costs for common illnesses can be financially disastrous for poor households with no insurance coverage. However, in our study, we found that even when covered by Chinese SHI, high-cost families could still face financial ruin. Health reform experiences in many western countries highlight that health systems requiring lower out-of-pocket payments for healthcare could offer better protection for the poor against catastrophic spending. ${ }^{22} 23$ Therefore, in the next stage of healthcare reform, Chinese SHI policymakers should understand that the few $(5 \%)$ high-cost families were the most costly to the healthcare

Table 6 Factors associated the high medical expenditures of high-cost families

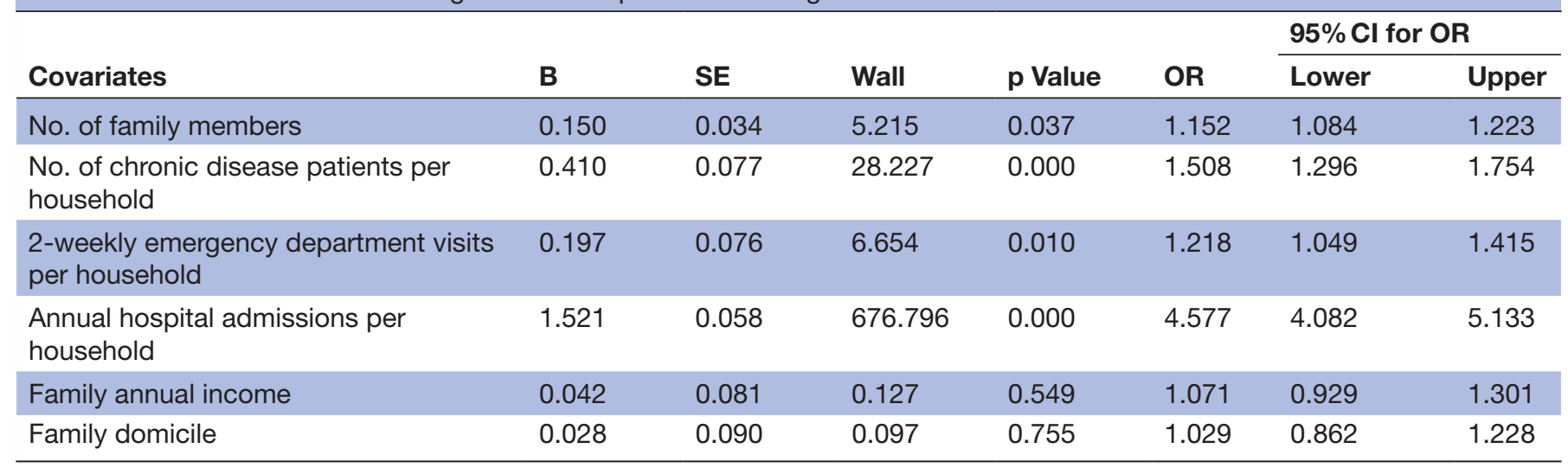


services, and policymakers should reimburse their medical expenses at a higher proportion to reduce the high out-of-pocket burden placed upon these families. ${ }^{24}$

The results of the binary logistic regression model is helpful to understand the characteristics of high-cost families and identify them. In the present study, we found that four factors-number of family members, number of chronic disease patients per household, 2-weekly emergency department visits per household, and annual hospital admissions per household-were associated with the high medical expenditures of a family and made it more vulnerable to financial risk. The first reason is that families with a larger population tend to need more medical care, and thus the total medical services utilised and medical expenditures are higher than for other families. The second reason is that the composition of high-cost families is different from that of the remaining families. In this study, high-cost families had a greater proportion of old-aged members and patients with chronic diseases within the household. Another possible reason is that the present SHI only has the responsibility for reimbursement, without taking into consideration the patients' rationale for using medical services. According to Yingchun et al, the inappropriate admission rates for a township hospital and a county hospital in a selected county in Hubei Province of China were $13.01 \%$ and $12.14 \%$, respectively. ${ }^{25}$ However, the New Rural Cooperative Medical Service System rarely monitored such inappropriate admissions. ${ }^{26}$ The inappropriate use of medical services might or should be one of the potential drivers of the high costs of some families.

It is noteworthy that high-cost families used more medical services than the remaining families and their high need might be related to family members who are older and suffer from chronic disease. A series of previous studies had proven that both groups were high utilisers and accounted for significantly more medical expenditures. For example, analysis of the national databases of Scotland showed that $34 \%$ of community members over the age of 65 falls at least once per year and $20 \%$ of them contacted a medical service for assistance. ${ }^{27} \mathrm{~A}$ study in China found that $54.9 \%$ of 4162 elderly people with cardiovascular disease received outpatient care and $17.7 \%$ received inpatient care over the past 12 months. ${ }^{28}$ Because these families need more medical services, health policymakers must be particularly vigilant about avoidable or preventable care utilisation in the healthcare system, which was a common occurrence and represented a significant component of high medical expenditures. Within the US setting, overuse and misuse of diagnostic testing, avoidable hospitalisation and rehospitalisation, and overuse of emergency department services caused approximately $30 \%$ of healthcare costs amounting to more than US $\$ 700$ billion wasted per year. High-cost patients accounted for $79.0 \%$ of inpatient costs, $9.6 \%$ of which were due to preventable hospitalisations; additionally, $43.3 \%$ of emergency department spending and $13.5 \%$ of inpatient spending were preventable among persistently high-cost patients. ${ }^{29}$ Policymakers and researchers suggested it was the responsibility of the medical profession to become cost conscious and decrease unnecessary care that does not benefit patients but represents a substantial percentage of healthcare costs. ${ }^{30}$ Some policymakers have foreseen the significance of the control of irrational medical services utilisation for the high-cost population. Many health projects or plans in the USA, such as the Complex Care Management Programme, the HealthCare Partners Medical Group, and the Patient-Aligned Care Team, Colorado Access, have been implemented to improve the management of care for high-cost Medicaid patients and to reduce their avoidable emergency department services and hospitalisations. ${ }^{31} 32$

However, in China and many other Asian and African countries with scarce health resources, the high-cost population has never been identified, and there are no health projects focusing on high-cost families. The findings in this study suggest that in the Chinese mainland care management programmes to promote the rational use of medical services and to control the medical expenditures of high-cost families should be explored and implemented by the SHI as soon as possible. ${ }^{33}$

The study's strengths comprise the investigation from a family perspective within large geographical areas. In addition, the binary logistic regression model was used appropriately to adjust the confounders and find the related factors with high medical expenses in the Chinese healthcare setting. However, the study had several limitations that should be noted. First, the data were collected only in Jiangsu Province, which is an economically developed province and might not be representative of other economically developing areas in China. Further research in other economically developing areas or at the national level is needed to provide comprehensive evidence for SHI policymakers. Second, although the high-cost population has attracted attention from many policymakers and researchers from the WHO and the USA over the past decades, there has been no consensus on the concept of high-cost population and identity standards. More theoretical studies should be carried out to determine the concept and measurement methods. ${ }^{34} 35$ Third, family composition is associated with the high cost of medical expenditures in this study; however, how certain family demographics mitigate specific types of spending still needs further exploration. Findings from studies that address this interesting problem may produce policy recommendations for high-cost population care management programmes to be designed and implemented by the Chinese SHI.

\section{CONCLUSION}

In conclusion, our analysis of the high-cost population from a family perspective suggests that although universal SHI has been set up in the Chinese mainland, its effectiveness in lowering high-cost families' risk of catastrophic 
health expenditure has been modest. As only a few highcost families account for half of the healthcare spending, future SHI designers should ensure as a priority that the out-of-pocket burden of this population is lowered. Further, care management programmes to promote the rational use of medical services and to control medical expenditures of high-cost families should be addressed by the SHI of China.

Acknowledgements The authors would like to thank the staff of the Health and Family Planning Commission of China's Jiangsu Province for their support to conduct the Fifth Health Service Investigation of Jiangsu Province (2013). The authors would like to thank Proffessor Jiaying Chen, who presided over the Fifth Health Service Investigation of Jiangsu Province (2013).

Contributors YM participated in the design of the study, performed the statistical analysis, drafted and revised the manuscript. LZ provided guidance on data analysis and policy suggestions. DQ and TY modified the manuscript. SS helped to edit the language, the introduction and the discussion. DH and YN helped to analyse the data and collect the references. All authors read and approved the final manuscript.

Funding This study was funded by the National Natural Science Foundation of China (NSFC, 71603132), the Jiangsu Province Social Science Fund (2014SJB159) and the Social Science Fund of Nanjing Medical University (2016ZSZ003).

Competing interests None declared.

Ethics approval National Health and Family Planning Commission of the People's Republic of China and Jiangsu Provincial Government.

Provenance and peer review Not commissioned; externally peer reviewed.

Data sharing statement The anonymised dataset is available through the email of the corresponding author.

Open Access This is an Open Access article distributed in accordance with the Creative Commons Attribution Non Commercial (CC BY-NC 4.0) license, which permits others to distribute, remix, adapt, build upon this work non-commercially, and license their derivative works on different terms, provided the original work is properly cited and the use is non-commercial. See: http://creativecommons.org/ licenses/by-nc/4.0/

(C) Article author(s) (or their employer(s) unless otherwise stated in the text of the article) 2017. All rights reserved. No commercial use is permitted unless otherwise expressly granted.

\section{REFERENCES}

1. Zulman DM, Pal Chee C, Wagner TH, et al. Multimorbidity and healthcare utilisation among high-cost patients in the US Veterans Affairs Health Care System. BMJ Open 2015;5:1-9.

2. Lester Feder J. Predictive modeling and team care for high-need patients at health care partners. Health Affairs 2014;33:1123-31.

3. QUINLIVAN RT. Treating high-cost users of behavioral health services in health maintenance organization. Psychiatr Serv 2000;51:159-62.

4. Xin $\mathrm{H}$. How do high cost-sharing policies for physician care affect inpatient care use and costs among people with chronic disease? J Ambul Care Manage 2015;38:100-8.

5. Sarnak DO, Ryan J. How high-need patients experience the health care system in nine countries. Issue Brief 2016;1:1-14.

6. Ronksley PE, Kobewka DM, McKay JA, et al. Clinical characteristics and preventable acute care spending among a high cost inpatient population. BMC Health Serv Res 2016;16:165.

7. Hayes SL, Salzberg CA, McCarthy D, et al. High-need, highcost patients: who are they and how do they use health care? A population-based comparison of demographics, health care use, and expenditures. Issue Brief 2016;26:1-14

8. Qin Z, Wenbin Z, Guoen L. Health insurance coverage and medical financial risks for Chinese households. Insurance Studies 2013;7:95-107.
9. Hui LI, Jing-Xia T, Jiang QIN. Metanalysis on the economic risks of diseases, catastrophic expenditure on health and its influence factors of urban families in Hami area. Chinese Health Economics 2015;34:48-50.

10. Pietz K, Byrne MM, Petersen LA. A decision-theoretic approach to identifying future high-cost patients. Med Care 2006;44:842-9.

11. National Bureau of Statistics of China. China statistical yearbook 2015, http://www.stats.gov.cn/tjsj/ndsj/2015/indexch.htm

12. Yip W, Hsiao W. Harnessing the privatisation of China's fragmented health-care delivery. Lancet 2014;384:805-18.

13. Hongmei YI, Yezhou YAO, Linxiu Z. Impact of New Rural Cooperative Medical Scheme on farmers'utilization of medical care and medical expenditure: evidence from panel data in 5 Provinces. Chin $\mathrm{J}$ Health Policy 2013;6:25-9.

14. Long $\mathrm{Q}, \mathrm{Xu} \mathrm{L}$, Bekedam $\mathrm{H}$, et al. Changes in health expenditures in China in 2000s: has the health system reform improved affordability. Int J Equity Health 2013;12:40.

15. Hougaard JL, Osterdal LP, Yu Y. The Chinese healthcare system: structure, problems and challenges. Appl Health Econ Health Policy 2011;9:1-13.

16. Izad Shenas SA, Raahemi B, Hossein Tekieh M, et al. Identifying high-cost patients using data mining techniques and a small set of non-trivial attributes. Comput Biol Med 2014;53:9-18.

17. Rais S, Nazerian A, Ardal S, et al. High-cost users of Ontario's healthcare services. Healthc Policy 2013;9:44-51.

18. Calver J, Brameld KJ, Preen DB, et al. High-cost users of hospital beds in Western Australia: a population-based record linkage study. Med J Aust 2006;184:393-7.

19. Saastamoinen LK, Verho J. Drug expenditure of high-cost patients and their characteristics in Finland. Eur $J$ Health Econ 2013;14:495-502.

20. World Health Organization. Designing health financing systems to reduce catastrophic health expenditure, 2005. http://www.who.int/ health financing/documents/cov-pb e 05 2-cata sys/en/

21. Xu K, Evans DB, Kawabata K, et al. Household catastrophic health expenditure: a multicountry analysis. Lancet 2003;362:111-7.

22. Xu K, Evans DB, Carrin G, et al. Protecting households from catastrophic health spending. Health Aff 2007;26:972-83.

23. Falkingham J. Poverty, out-of-pocket payments and access to health care: evidence from Tajikistan. Soc Sci Med 2004;58:247-58.

24. Okumura $\mathrm{Y}$, Ito $\mathrm{H}$. Out-of-pocket expenditure burdens in patients with cardiovascular conditions and psychological distress: a nationwide cross-sectional study. Gen Hosp Psychiatry 2013;35:233-8.

25. Xiaoyan C, Shuo Z, Cheng W, et al. Effects of the inappropriate admission patients under New Rural Cooperative Medical System on the use efficiency of hospital fund in a county, Hubei. Medicine and Society 2013;26:9-11.

26. Zhu S, Xiaoyan $\mathrm{C}$, Cheng $\mathrm{W}$, et al. The implication of research on inappropriate hospital admissions overseas. Medicine and Society 2013;26:15-17

27. Craig J, Murray A, Mitchell S, et al. The high cost to health and social care of managing falls in older adults living in the community in Scotland. Scott Med J 2013;58:198-203.

28. Dou L, Liu X, Zhang T, et al. Health care utilization in older people with cardiovascular disease in China. Int J Equity Health 2015;14:59.

29. Joynt KE, Gawande AA, Orav EJ, et al. Contribution of preventable acute care spending to total spending for high-cost Medicare patients. JAMA 2013;309:2572-8.

30. Weinberger SE. Providing high-value, cost-conscious care: a critical seventh general competency for physicians. Ann Intern Med 2011;155:386-8.

31. Hong CS, Siegel AL, Ferris TG. Caring for high-need, high-cost patients: what makes for a successful care management program? Issue Brief 2014;19:1-19.

32. Institute of Medicine. The healthcare imperative: lowering costs and improving outcomes. Washington, DC: National Academies Press, 2010.

33. Billings J, Mijanovich T. Improving the management of care for highcost Medicaid patients. Health Aff 2007;26:1643-54.

34. Gregori D, Petrinco M, Barbati G, et al. Extreme regression models for characterizing high-cost patients. J Eval Clin Pract 2009;15:164-71

35. Chang HY, Boyd CM, Leff B, et al. Identifying consistent high-cost users in a health plan: comparison of alternative prediction models. Med Care 2016;54:852-9. 